\title{
Application of Robotics in Higher Education in Industry 4.0 Era
}

\author{
Yanna $\mathrm{He}^{1, *}$, Liying Liang ${ }^{2,3}$ \\ ${ }^{1}$ Endicott College of International Studies, Woosong University, South Korea \\ ${ }^{2}$ Woosong University, South Korea \\ ${ }^{3}$ Yonsei University, South Korea
}

Copyright $\mathrm{C} 2019$ by authors, all rights reserved. Authors agree that this article remains permanently open access under the terms of the Creative Commons Attribution License 4.0 International License

\begin{abstract}
As one of the most destructive technologies in the Industry 4.0 Era, robotics has been applied into higher educational practices. In this paper, we critically review the current situation of robotics application in higher education. Taking a quantitative research method, we survey both instructors and students to have a general view of how they perceive robotics in their teaching and learning process, respectively. We find no statistical differences by gender groups and country of origin for instructors and students. At last, we discuss obstacles hindering the development and wide popularization of robotics in high education institutions and put forward some tentative suggestions for the future spread of robotics in higher education. The findings of this paper would be of interest for educators, national policy makers and students.
\end{abstract}

Keywords Higher Education, Industry 4.0, Instructors, Robotics, Technology

\section{Introduction}

\subsection{Robots and Robotics}

Digitization in the Industry 4.0 Era affects our life by multiple directions including higher education (Burrit and Christ 2016). As one of the most destructive technologies, robotics is assumed to benefit educational parties ranging from instructors to students. Although robotics is used for educational purposes, both instructors and students are not aware of their application of such technologies as most of them assume robotics as robot.

The word robot came from a Czech play writer Karl Kapek's Rossum's Universal Robots in 1920, which means for worker or serf in Czech, while the term robotics was believed to be coined and popularized by Issac Asimov (Williams, 2016), who was named as the Father of Robotics for his Three Laws of Robotics. Over the years, so many researchers and institutions have made attempts to define what robot and robotics are, yet no common definitions have been made. Mataric (2007) defined robot from a broad sense as an autonomous system, which exists in the physical world, can sense its environment, and can act on it to achieve some goals.

There are various conceptions of robotics with different emphases and perspectives. In the Digital Transformation Initiative: Maximizing the Return on Digital Investments (World Economic Forum [WEF], 2018), robotics is referred to encompassing the design, construction, implementation and operation of robots. To be more specific, robotics is an interdisciplinary branch of subject that deals with robot-related science and technology and its application and covers artificial intelligence, automation, sensors mechanical engineering, electrical engineering, computer science and others (Cai, 2011).

With the advent of Industry 4.0, robots and robotics are moving beyond industrial application confined to manufacturing plants, whereas they are also making their ways into classrooms, hospitals, offices, homes and people's other aspects of daily lives (Khatib, Yokoi, Brock, Chang, \& Casal, 2001). In this study, the authors will mainly focus on the perception of robotics, and its applications in higher education.

\subsection{Robotics in General}

As the WEF indicated in its White Paper Eight Futures of Work: Scenarios and their Implications (2018), automation, primarily in the form of robotics, artificial intelligence and other new technologies, is developing at an unprecedented rate, and is having a significant impact on multiple aspects of life. Digital Transformation Initiative: Maximizing the Return on Digital Investments, a System Initiative on Shaping the Future of Digital Economy and Society (WEF, 2018) demonstrates that return on investment in technologies such as mobile/ social media, internet of things (IoT) and cognitive technologies is overall positive, while robotics yields the highest productivity increase (Figure 1) as advanced robotics have widely been seen to be applied in manufacturing, services and other industries to generate productivity increases. 


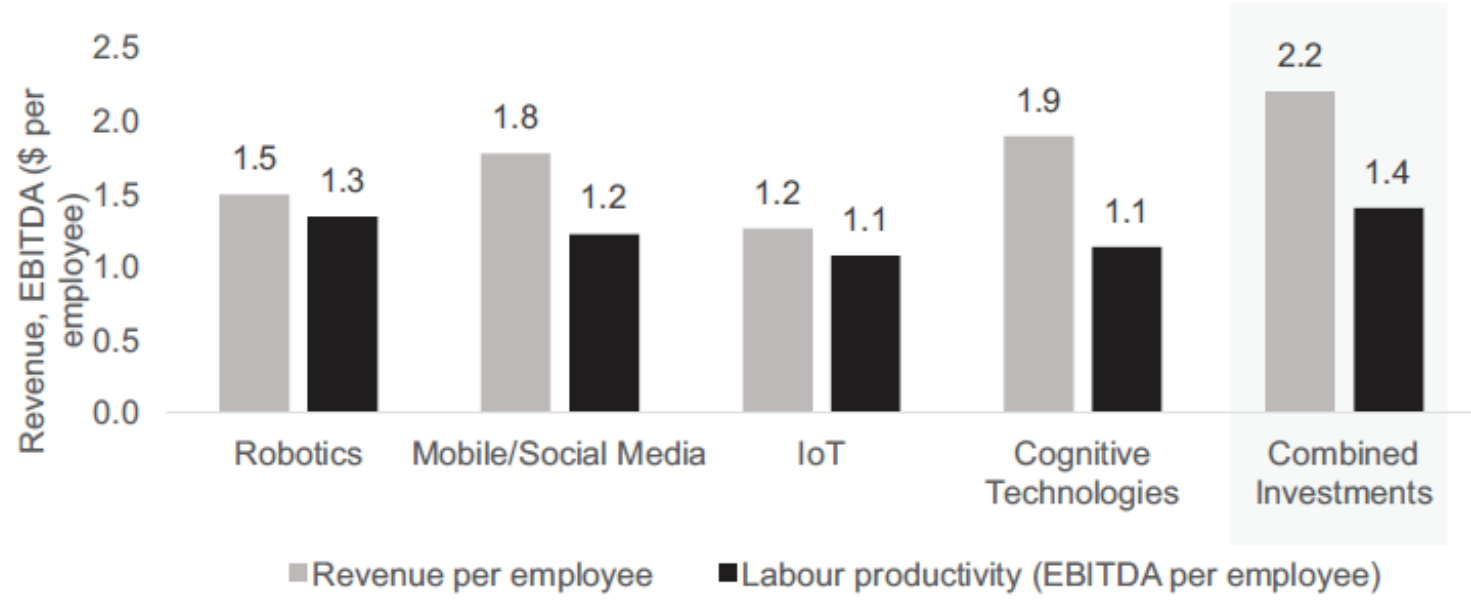

Retrieved from Digital Transformation Initiative: Maximizing the Return on Digital Investments, WEF

Figure 1. Return on Investment by Technology (2015-2016)

Robotics has been effectively used for industrious purposes to increase productivity. At the same time, the interest in applying robotics for educational activities has also increased over the past few years. There have been attempts to introduce robotics to schools ranging from kindergarten to secondary (high) schools, mostly for Science, Technology, Engineering and Mathematics (STEM) subjects (Eguchi, 2016). However, the potential for applying robotics and other technologies into schools can be tapped further, as recent surveys suggest that technology has not yet been effectively used for facilitating meaningful learning in schools (Ertmer, \& OttenbreitLeftwich, 2013). Among various levels of schooling, higher education has drawn special public attention for their roles in providing approaches to science, technology, and research that contribute to economic development (Koc, 2013). Robotics, identified as one of the most transformative technologies due to its widespread application, ability to drive significant efficiencies, and impact on labor, is among seven technologies expected to come of age and create a level of disruption which has never been seen before over the next 10 years, according to a WEF report the Future of Jobs: Employment, skills and workforces for the fourth industrial revolution (WEF, 2016). In a WEF White Paper, The Next Economic Growth Engine: Scaling Fourth Industrial Revolution Technologies in Production (2018), it states clearly that a strengthened collaboration between government, business, academia and civil society would be required in order to adopt technology at scale and to diffuse it to achieve economic and societal impact and maximize productivity benefits. Therefore, higher education instructors are expected to integrate the latest information and telecommunication technology (ICT) into classrooms to enhance professional teaching and students' learning.

In addition, Executive Summary World Robotics 2017
Industrial Robots Report issued by the International Federation of Robotics [IFR] (2017) concluded a continued accelerating growth in robotics sales globally, with China being the world' biggest robot market since 2013. As the market with the biggest share, $30 \%$ of the total supply in 2016 and $27 \%$ in 2015, China almost came to the total sales volume of Europe and the Americas together. And according to the World Robotics Report 2018 (IFR, 2018) China saw the largest growth in demand for industrial robots in 2017, up 58\%. However, China is estimated to have a shortage of advanced numerical control machine (NCM) and robotics expertise (Ministries of Education, Industry and Information Technology, and Human Resources and Social Security of the People's Republic of China, 2016) in the coming few years (Table 1).

China is an example of the large robotics market demand on talents, while higher educational institutions are major talent pools. Thus, this paper examines the perception of robotics among college students as well as its application in higher education, and presents some suggestions and policy implications, for educational shareholders, national policy makers, instructors, and students, for the widespread anticipated popularization of robotics in the near future.

\section{Literature Review}

\subsection{Research on the Application of Robotics in Education}

When searched with keywords of "robotics" and "education" in Science Direct, a leading platform of peer-reviewed scholarly literature, a total of 24,162 results were found from 1995 to 2019 . Over the last 10 years, research on robotics and education has seen continuous growth (Table 2). 
Table 1. Estimated Total Talents in Advanced NCM and Robotics in China (Unit: 10,000 Persons)

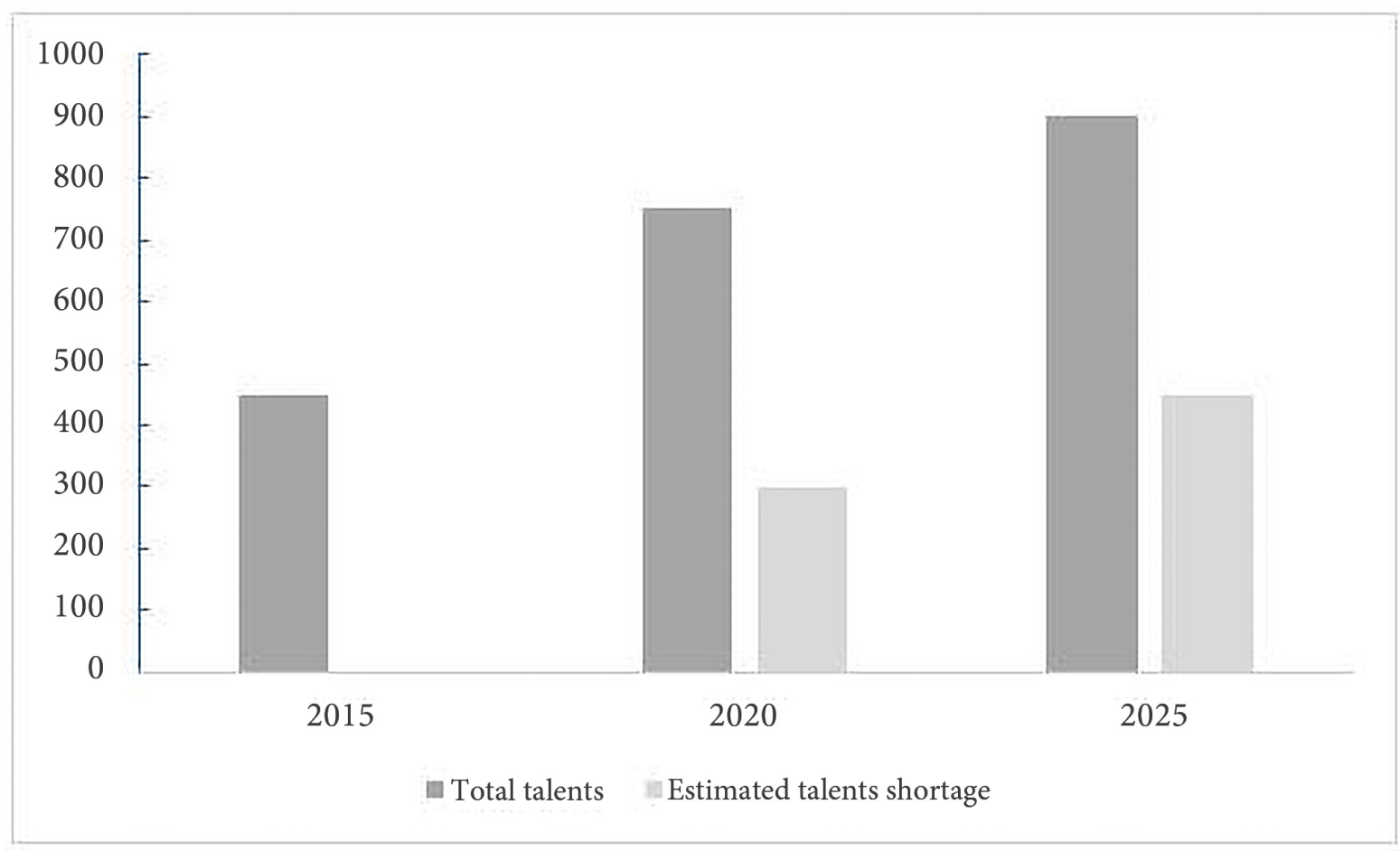

Retrieved from http:/www.miit.gov.cn/n1146290/n4388791/c5500114/content.html

Table 2. Results Found with Keywords of "Robotics" and "Education" in Science Direct

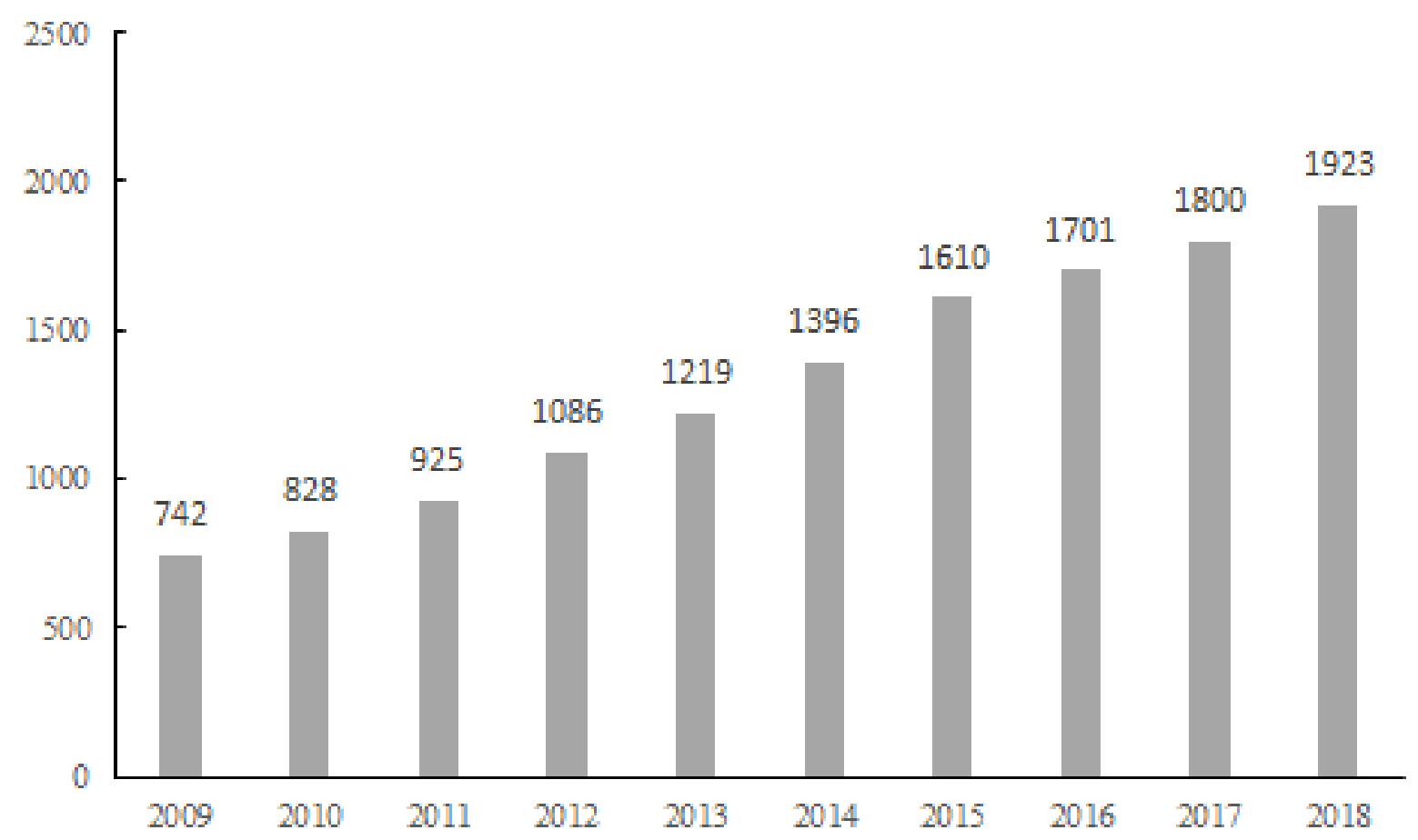


Topics on robotics and education vary greatly. Mubin, Stevens, Shahid, Mahmud and Dong (2013) outline the major dimensions classifying research on robotics applications in education as follows: i). subject of the robotics-related learning; ii). location of the learning activity; iii). the role of robotics during the learning process; iv). types of robotics used in education; and $\mathrm{v}$ ). pedagogical theories applied for the research.

Additionally, there are several personal characteristics, which might influence the acceptance of robotics and other technologies in classrooms. Variables considered to influence participants' acceptance of technology in education are students' individual personalities or gender (Syrdal, Dautenhahn, Woods, Walters, \& Koay, 2007), instructors' instructors' capacity to use technology for teaching about using technology for teaching (Albion, 2001), a robot's responsiveness, age of students (Birnbaum, Mizrahi, Hoffman, Reis, \& Finkel, 2016), localization and mapping of mobile robotics (Mahmood \& Rodriguez, 2017), and level of study of students (Díaz, Nuno, Saez-Pons, Pardo, \& Angulo, 2011), to name but a few. Kuo et al (2009) found that male participants showed a more active attitude towards robotics and were more eager to interact with robotics when compared to female participants (Heerink, Kröse, Evers, \& Wielinga, 2010).

However, few studies have been focused on the perception of robotics among college students and their instructors as well as its application in higher educational institutions. Such being the case, a study on the general perception of students and instructors in higher education on robotics and its application in their learning environment would be of practical significance to discipline development and innovation, cultivation of talents, and national strategy making and planning.

\subsection{National Strategy for Robotics Development in Major Developed Countries}

Based on the Executive Summary World Robotics 2017 Industrial Robots (IFR, 2017), Asia is the strongest growth market for robotics in the world. Of the world's five key robotics markets, China is the only developing country while the other four are major developed countries. In 2016, 'A Development Plan of Robotics-related Industries' (2016-2020) outlining the current robotics development situation was issued by the Ministries of Education, Industry and Information Technology, and Human Resources and Social Security of the People's Republic of China (2016). It noted that those countries with a developed industry have established an industrial system featuring improved industrial robotics. These economies have occupied a leading role in core robotics technologies and their products, giving rise to several robotics enterprises with a cutting-edge advantage among the world's robotics industry over the years. In particular, these economies have made the development of robotics a national strategy after the global financial crisis in 2008, aiming at maintaining their leading economic position in the world (Ministries of Education, Industry and Information Technology, and Human Resources and Social Security of the People's Republic of China, 2016).

Then the discussion goes to America, the world's third major robotics market in 2016. As the largest economy in the world, the United States ranked fourth in the 2016 robot market with an increase in robot installations to a peak of 31,400 units per year (IFR, 2017). On June 24, 2011, the then-President Obama launched the Advanced Manufacturing Partnership (AMP), which is a national effort that ensures major investments would be made in next-generation robotics research and other key areas (White House, 2011). This step aimed to help create the next generation of robots that would work closely with human operators, bringing in new labor ability and carrying out dangerous and difficult tasks. In addition, one of the key higher educational institutions in the U.S., MIT, \#1 in the QS World University Rankings for seven consecutive years since 2012 (QS Top Universities, 2018), set up a program of designing and building LEGO-based robots for engineering students to improve their ability in design and creation and to integrate the robotics education and engineering experiments as early as in 1994 (Yang \& Qiao, 2017). Currently robotics has become an indispensable part of the higher education curriculum in U.S. among world renowned universities such as MIT, Carnegie Mellon University, University of California-Berkeley, the Johns Hopkins University, and Stanford University.

Finally, this research also examines the world's second-largest robotics market, Europe. In January 2011, the German Federation of Industrial Research Associations (AiF) launched a high-tech strategic initiative, advocating for the development of Industry 4.0 as one of ten key projects for 2020. As an indispensable part of intelligent manufacturing and assembly, robotics is a critical link in the Industry 4.0 Initiative (Yang \& Qiao, 2017). According to a Chinese news report, in 2016, Technische Universität München, a German higher education institution, and LIECTROUX, a German high-tech enterprise, signed an agreement to jointly launch a robotics-engineering program and began to enroll students the same year. This was the first-time intelligent robotics engineering had been offered in a German higher education institution, aiming to cultivate specialists in robotics disciplines and provide technological support for advancing the Industry 4.0 development strategy. The integration of higher education institutions and enterprises and researches has also found a new pattern for cultivating robotics talents, enabling students to apply what they have learned in the classroom to their work, and in return to better learn robotics-related knowledge with practical working needs.

In order to better understand how instructors and students perceive robotics in higher education, we 
therefore conduct an empirical study on perception of robotics-related technology. In the following part, we will discuss about sampling, data collection procudures and statistical analyses conducted.

\section{Methodology}

\subsection{Sampling and Data Collection}

We employ a convenience sampling method to collect information from some participants who are of the same institution with researchers and thus recommended by Etikan, Musa and Alkassim (2016) for easily access to the researchers for study participation. Both online and offline surveys are used to collect effective responses. As a remark, the researchers ask the university board for written consent and professors for written permission of collecting data for academic use only prior to data collection procedures. We carry out the survey in accordance with ethical guidelines of the university.

For the offline questionnaires, researchers went to a classroom where students are having their class. Researchers explain in detail to the respondents what the survey is about and ask whether they would voluntarily to fill in a printed questionnaire on the perception of application of robotics-related technology in their learning. Also, researchers state clearly that no penalty would arise for refusal to participation. Since the city where the university located is known as the technological center of the country, students have used robotics-related technology in their study and thus are of a better understanding of such application. After the class, an effective copy of 29 questionnaires is collected out of 31 copies dispatched.

As the survey intends to have a better understanding of how participants perceive robotics-related technology, we thus take advantage of online platform to collect information. We publish and invite for participants through two forms of online surveys, one for professors and one for students respectively. We state explicitly that the surveys are for students and professors of high institution only and surveys are conducted in an anonymous manner. The online data collection last for 24 hours and we get effective responses from 52 professors and 175 students worldwide. In total, we have 52 professor and 204 student respondents.

\subsection{Instrument}

The researchers first interview several professors and students separately in a pilot study. We find that both professors and students are not aware of their use of robotics despite of the fact that they are actually employing such technology in their teaching and learning process. Then we deem it necessary to run a survey to have a general picture of how they perceive such technology in higher education.

Boynton and Greenhalgh (2004) suggest that questionnaires provide an objective means of collecting information of knowledge, attitudes, and behaviors from respondents. In this study, the researchers develop two questionnaires based on literature on robotics-related technology and its application for educational purposes. Before questionnaires are sent to respondents, a native English speaker is asked to check the words and expressions. Then a Chinese and South Korean student are intentionally chosen for further pilot study for any misunderstanding of the language. The questionnaire is finalized subsequent to a double check of language and wording.

The questionnaire for professors and students is comprised of two parts: (i) literature-based demographics questions such as participants' gender and nationality. (ii) several items of Likert scale (from Strongly Agree to I don't know/NA) questions on perception of robotics-related technology in higher education. Conole, De Laat, Dillon and Darby (2008), and Levin \& Hansen (2008) indicate that students' perception of the usefulness of instructional technology could be used as an indicator of both students' intent to use such technology and whether technologies have value in the learning environment. And research in this respect could be valuable when it helps educators and policy makers in their decisions.

Before we analyzed the data, a dummy variable AGREED is created based on level of statements. We first remove "I don't know/NA" responses which are selected by only few respondents. Then we define AGREED as 1 for "Strongly Agree" and "Agree" responses and otherwise 0. Subsequent to statements redefine, descriptive analyses are run to investigate participants' general perception on robotics-related technology and application in higher education. We also run t-tests to see gender differences, as well as of gap between Chinese respondents, both professors and students, and the rest of respondents. In the following section, statistical results will be presented and tabulated.

\section{Results}

This study is conducted to explore the general perceptions of students and instructors of higher education on robotics-related technology and its utilization in learning and teaching. Both online and offline questionnaires are employed for the stud. A total of 52 effective responses are collected from professors who are currently teaching and 204 responses from students studying in the higher educational institutions.

Figure 2 demonstrates Likert-scale statement results of students' responses sorting out by mean scores. As a trend, 
all students seem to agree on all statements on robotics-related technology. The highest scores items $(\mathrm{M}=0.88)$ are beliefs about the benefits of technology and skills are an indispensable part of academic success for students. The least scored item $(M=0.59)$ is about the potential threats of technology posed to their future job opportunities. We further conduct several rounds of t-tests to see whether there are any differences between female and male respondents, as well as respondents of Chinese and other nationalities. Interestingly, we find no statistical differences across gender groups and country of origin.

Then we investigate professors' responses by degree of agreement with statements. Figure 3 shows share of instructors' respondents by Chinese South Korean nationality, respectively. Both Chinese and Korean professors unanimously and tend to strongly agree that technology skills are essential to students' future career success. Similarly, professors of different country of origin hold that integration of technology into classroom teaching is challenging for them. However, there are less Chinese professors, relative to Korea counterparts, who take technology integration into teaching process is a challenge for them. Furthermore, Chinese professors are less likely to allow their students to have access to digital devices, which is thought to easily distract students' during instruction. Overall, all professors agree that application of technology in classroom benefit both students and instructors.

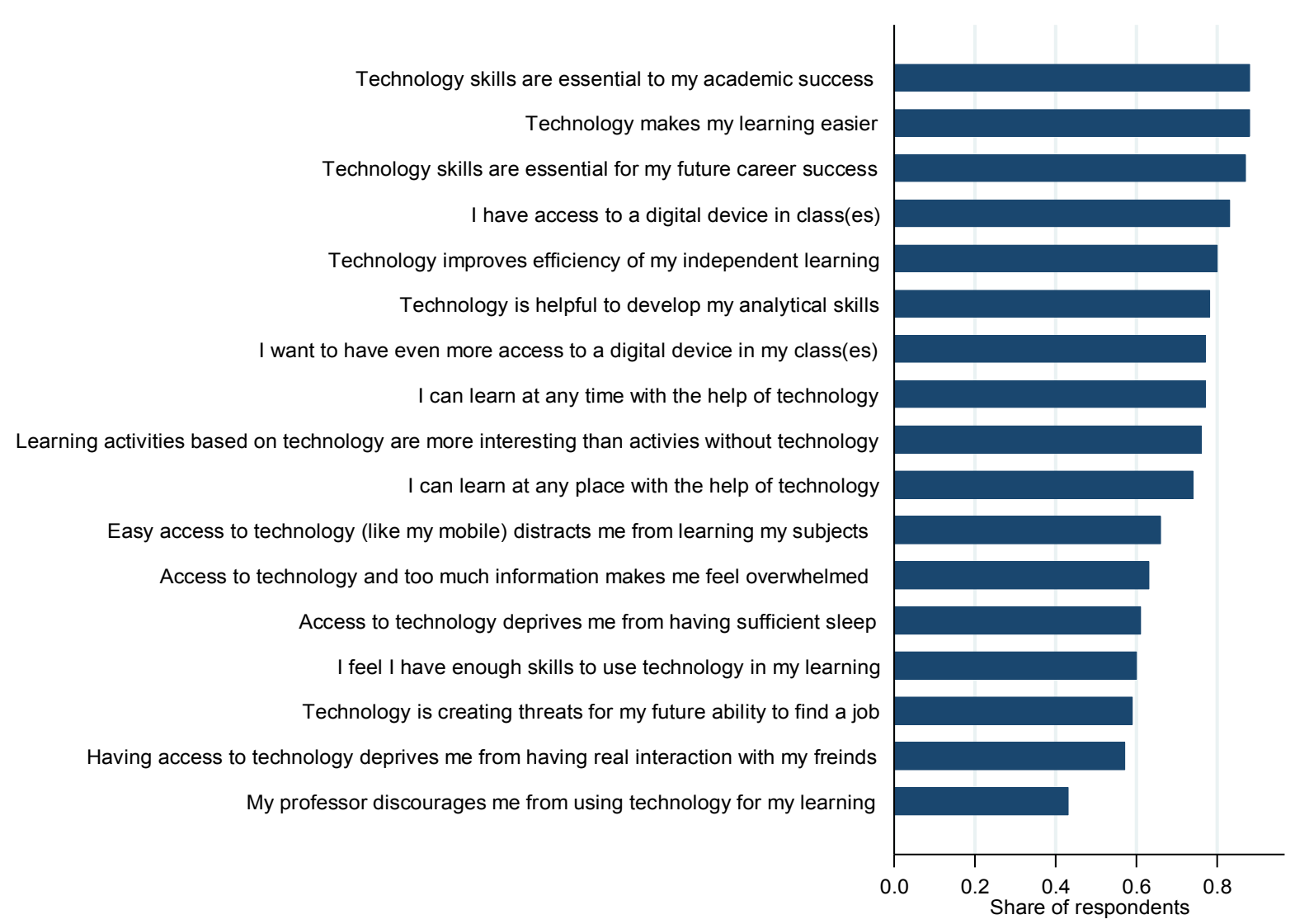

Figure 2. Share of students' respondents sorting out by mean scores 


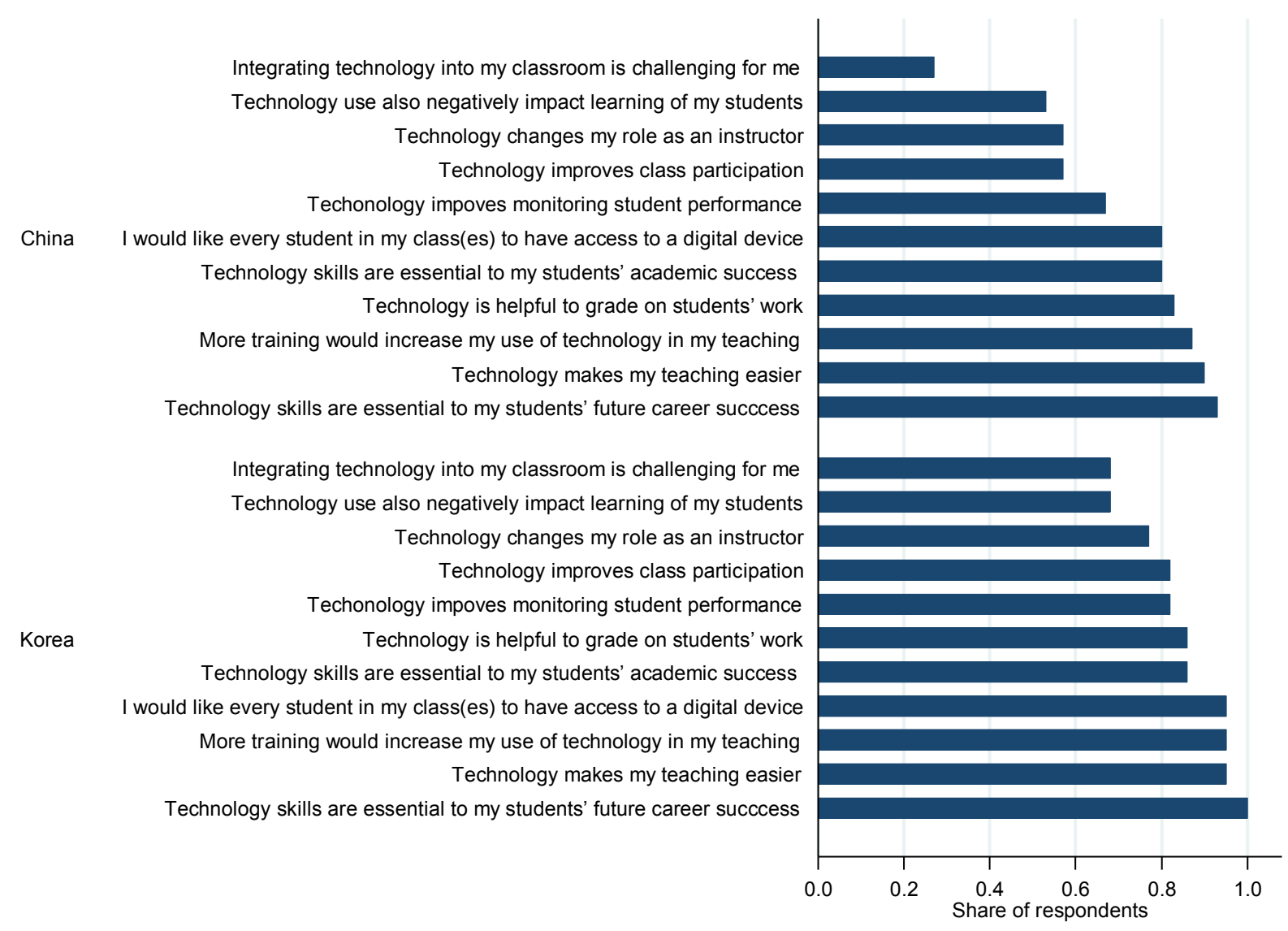

Figure 3. Share of professor respondents by country sorting out by mean scores

\section{Discussions}

Robotics has developed from a study solely based in research to one, which now includes activity-based learning for students of different ages and abilities (Mcdermott, 2006). Its application in education is a growing field that could not only have an effect on STEM education at various levels (Alimisis, 2013). Studies have yielded positive feedback from involved students, instructors and researchers on integrating robotics into classroom teaching and research (Kandlhofer \& Steinbauer, 2016). In the following section, contribution of robotics application in higher education will be discussed from the perspectives of both students and instructors.

\subsection{Robotics Learning is of Practical Significance to Students}

The application of robotics is helpful to enrich discipline contents and develop students' various abilities. Moreno, Quevedo, Llinás \& Hernández-Brito (2015) maintain that traditional style of education centered exclusively on knowledge blocks in STEM and other subjects do not integrate with each other. However, robotics, as an interdisciplinary subject, could help change such a dilemma in which students acquire knowledge in a passive manner and lack learning motivation (Moreno et al., 2015).
As an interdisciplinary subject, robotics covers a wide range of computer, machinery, electrical, telecommunications, control and other related knowledge. Therefore, wider teaching of robotics would be conducive to discipline integration and innovation.

Robotics applications in education could also act as a supplement for Project Based Learning (PBL), which was first put forward by John Dewey in 1897. This student-oriented pedagogy that involves an active classroom approach encourage students to learn by doing so that they acquire real knowledge through positive exploration of challenges and problems in the learning process (Zadok \& Voloch, 2018). To put it in another way, students could learn more effectively through applying the classroom knowledge they have learned into practice at the same time when they are leaning than the traditional way of learning in which the difficult knowledge such as physics and electricity is separated from their practical application.

In a study where robotics was taken as a curricular subject and participants learnt the basics of designing, building, and programming robots, it was found that participants had maintained their curiosity during the whole process, from the discipline-specific knowledge of robot construction and programing, to human and organizational values such as personality development, group working, creative thinking, and analytical of problem solving (Scaradozzi, Sorbi, Pedale, Valzano, \& 
Vergine, 2015).

In addition, the application of robotics in education enhances students' classroom participation and strengthens their confidence. In Robot-Assisted Instruction (RAI), robots act as an assistant or a complement to instructors, providing an additional learning tool and enlivening the classroom atmosphere for students. Jones, Jo and Han (2006) advance the term "ubiquitous robotics", to denote seamlessly integrating robots into the physical world as user friendly educational assistants, utilizing artificial intelligence (AI) and speech and language processing technology. An example in this respect is the chatbot, used first in retail and finance but then applied in the educational sector. Kerly, Hall and Bull (2006) suggest an expected exponential growth in chatbots as computing technology and the cooresponding language processing softwares advance. Edcuational chatbots could improve students' classroom participation, as some students are too shy to ask questions in front of classmates. For those students, chatbots could provide students with immderiate answers for daily homework, assignment deadline, and FAQs, which helps relieve embarrassment and awkwardness and therefore build stronger confidence.

Furthermore, Choi Mun-taek, a senior South Korean research engineer explains educational robot systems are beneficial for increasing students' interest and self-motivation in learning language subjects according to the government evaulations (see Park, 2010). And with the development of human-robot interface technology, home-based e-learning is available for billions of people to participate, learn and exchange in different corners of the globe at the same time. These e-learning software robots, on the one hand, enable anyone who has access to the internet to get interesting resources regardless of time and place limits or physical disability (Jones, Jo \& Han, 2006), and make it possible for those limited valuable online resources to benefit the largest audience.

\subsection{Robotics Teaching Does Benefits to Instructors}

The advancement of science and technology and the internet has changed the traditional ways and tools of teaching, in which teachers give lectures and students are busy taking notes. Nowadays, virtual classrooms, far-distant teaching systems, and online classrooms broadcating live are quite familiar to the public, and in recent years, robotics has shown a great potential in instrcution management such as planning, organizing, coordinating and controlling teaching affairs and equipment, and other pedagogical methods have been introduced into the classroom as an assistant for teachers (Ospennikova, Ershov, \& Iljin, 2015).

Integration of robotics in higher education enables instructors to enrich teaching methods and classroom activities. Robotics applications in classrooms have multiple advantages, for example allowing students to adjust the speed of data presentation, repeat instructions, and access multimedia resources with vivid visual, mechanical and sound effects (Ospennikova et al., 2015). These advantages can complement instructors' teaching and helps to enliven classroom atmosphere, explain sophisticated knowledge, demonstrate experimental processes, and so on.

Robotics is also credited with reducing behavioural issues and supporting positive student interactions. Application of robotics in higher education benefits both students and instructors. Its application in higher education is beneficial to the students for devloping their collaboration, communication, and problem-solving (Aurini, Mclevey, Stokes, \& Gorbet, 2017) as well as their innovative and logical thinking, group-working ability development and broader personal interests cultivation. At the same time, robotics could be used as a complementary way of instructors in some areas and disciplines to save istructors from repititious demonstration, to better optimize teaching resources, and to enrich instruction forms and activities.

\subsection{Obstacles of Widespread Application of Robotics in Higher Education}

Recent research (Alimisis, 2013; Kim et al., 2015; Eguchi, 2016) shows that robotics has drawn teachers and researchers' attention as a usuful tool to develop students' cognitive and social skills to support learning especially for STEM subjects. Currently robotics is a reality in university classrooms in some countries such as South Korea and Japan (Yang \& Qiao, 2017), yet it would be a long time before robotics could lead a classroom without the help of instructors (Park, 2010) to overcome diversified challenges.

First of all, the development of robotics is faced with hardware and software Challenges. As development of robotics has been accepted as a key part of the national strategy in many major developed countries and some developing countries, financial and policy supports for priority development were provided. However, as one of the key disruptive techonologies in the twenty-first century, robotics technology is still in its developmental stage and its integration into higher education is subject to technological change. Gerecke and Wagner (2007) suggested that the effective use of robotics in higher education would require appropriate hardware platforms and software frameworks, which integrated didactic concepts, and a way allowing teachers from different subjects to easily design courses and share materials and knowledge.

On the contrary, the concern over the introduction of hardware or code which might affect operational integrity in the manufacturing industry led to a slow speed of robotics development, according to the WEF White Paper in collaboration with A.T. Kearney: Shaping the Future of 
Production: Four Contrasting Perspectives in 2030 (2017). Aurini et al. (2017) did an action research study of nine Ontario schools for their use of robotics and found that many instructors do not have their own robotics kits. The use and maintainence of these kits remains a problem as some teachers find no one to turn to for help when the kits go wrong. Furthermore, the lack of standardized programming methods remains a challenge for the development of robotics (Basteris \& Contu, 2018). Additionally, as the integration of robotics into classroom teaching requires an internet connnection in some cases, poor internet access and Wi-Fi coverage make it difficult for instructors and students to access apps or websites for assignment completion.

In addition, insufficient qualified instructors and discontinuous curriculum are also posing challenges for robotics development. Robotics education is of more significance for a general education for all people with fluency or literacy with advanced technologies than offering vocational skills for future STEM employees (Alimisis, 2013). As mentioned in the introduction, robotics is an interdisplinary branch of study and therefore both the instuctors and students engaged in it should be equiped with multidisplinary knowledge and skills. It would be easy to find an instructor who is specilized in automation, physics, mechanical or materials, however, it would be challenging to find enough qualified instructors who are knowledgeable in all of those mentioned fields at the same time.

Such is the case, too, for higher education students. Higher education robotics courses center on offering basic mechanical and engineering concepts (Sampsel, Bharwani, Mehling, \& Smith, 2011) to the students as most only have relatively limited knowledge of robotics when they first enter their institutions. There is no consistent curriculum for them from elementary school to high school. Benitti (2012) contends that robotics activities usually take place only for extracurricular activities such as summer camps and are not included in the school curriculum when students are pursuing secondary education. Therefore, when these students start their higher education, they are less likely to have a solid foundational knowledge of robotics.

Lastly, with the development of digitalization and automated robotics, both instructors and students have concerns over unemployment. An insight report by the World Economic Forum's System Initiative on Shaping the Future of Consumption Prepared in collaboration with Bain \& Company: Future of Consumption in Fast-Growth Consumer Markets: China (2018) illustrated that China is already and would continue to be a huge robotics market in the coming decade, as robotics could lower the cost of customized product design and service provision, which is the trend in the future. The above-mentioned report (WEF, 2018) stated that while manufacturing and other labor-intensive industries have created job opportunities for the majority of China's urban employed population, these low-skilled jobs are easily replaced by robotics and AI with higher efficiency and productivity.

Studies (Kim et al., 2015; Garcia-Murilloa, MacInnesb, \& Bauerc, 2018) also show that recent technological advances in disruptive technologies such as robotics and AI are going to exert a negative effect on current employment opportunities for human labor within a short period. This decline of employment will especially be true for labor-intensive industries, and for low and medium income jobs which require repeated and simple skills.

While there are concerns that robotics and automation could cause an increase of the unemployment rate, the report Towards a Reskilling Revolution: A Future of Jobs for All, a WEF insight report in collaboration with the Boston Consulting Group (2018) demonstrated that overall employment levels remained stable for their sample companies over the past ten years. Furthermore, Kim et al. (2015) showed a large-scale substitution of machine labor for human labor would not take place within the foresable future due to occupational creativity and government intervention. Successful individuals will be those who can work with these desruptive technologies.

\section{Conclusions}

In this paper we review the current situtation of robotics research and the development of robotics as a national strategy for major economies of the world. Then we conduct both online and offline suurveys to understand the general perception of robotics application in higher edcuational practices from from the perspectives of both instructors and students. We find no statistical difference to perception of robotics-related technologies by female and male respondents for both students and profesors. Similarly, there is no country-level differences in how do learners and educators in higher education perceive such disruptive technologies.

Later on, we discuss benefits and drawbacks of robotics applications in higher education and explores possible drawbacks hindering robotics development. On one hand, robotics is of great benefits to students for creative thinking, group building, analytical skills and self-learning. On the other hand, instructors also perceive robotics an an assitant to their instruction, which is helpful in grading homework and monitoring class performance. However, robotics development is challenged by both insufficient hardware and software technological support, inadequte subsidies, not enough qualified instructors and unemployment concerns.

Although there are studies comparing the effects of using robotics in elementary and secondary schools, there are less empirical studies on the real effect of appling robotics in the context of higher education. A next step of the research could be to explore the treatment effects of 
robotics in higher education.

\section{REFERENCES}

[1] Albion, P. R. (2001). Some factors in the development of self-efficacy beliefs for computer use among teacher education students. Journal of Technology and Teacher Education, 9(3), 321-347.

[2] Alimisis, D. (2013). Educational robotics: Open questions and new challenges. Themes in Science and Technology Education, 6(1), 63-71.

[3] Aurini, J., Mclevey, J., Stokes, A., \& Gorbet, R. (2017). Classroom robotics and acquisition of 21 st Century competencies: An action research study of nine Ontario school boards. Retrieved from http://ontariodirectors.ca/C ODE-rob/Robotics_Final_Report_Sept_22_2017.pdf

[4] Basteris, A., \& Contu, S. (2018). Software platforms for integrating robots and virtual environments. Rehabilitation Robotics, 159-173. https://doi.org/10.1016/B978-0-12-811 995-2.00012-6

[5] Benitti, F. B. V. (2012). Exploring the educational potential of robotics in schools: A systematic review. Computers \& Education, 58(3), 978-988. https://doi.org/10.1016/j.compe du.2011.10.006

[6] Birnbaum, G. E., Mizrahi, M., Hoffman, G., Reis, H. T., Finkel, E. J., \& Sass, O. (2016). What robots can teach us about intimacy: The reassuring effects of robot responsiveness to human disclosure. Computers in Human Behavior, 63, 416-423. doi: https://doi.org/10.1016/j.chb.2 016.05 .064

[7] Boynton, P. M., \& Greenhalgh, T. (2004). Selecting, designing, and developing your questionnaire. BMJ, 328(7451), 1312-1315. doi: 10.1136/bmj.328.7451.1312

[8] Burrit, R., and Christ, K. (2016). Industry 4.0 and environmental accounting: A new revolution. Journal of Sustainability and Social Responsibility, 1, 23-38.

[9] Cai, Z. X. (2011). Cai Zixing: Artificial intelligence vs human intelligence: A lecture on robotics [Video file]. Retrieved fromhttp://open.163.com/movie/2011/10/Q/P/M 7GFG4ES8_M7J1GDBQP.html

[10] Conole, G., De Laat, M., Dillon, T., \& Darby, J. (2008). 'Disruptive technologies', 'pedagogical innovation': What's new? Findings from an in-depth study of students' use and perception of technology. Comparative Education, 50(2), 511-524. https://doi.org/10.1016/j.compedu.2007.09.009

[11] Díaz, M., Nuno, N., Saez-Pons, J., Pardo, D. E., \& Angulo, C. (2011). Building up child-robot relationship for therapeutic purposes: From initial attraction towards long-term social engagement. Face and Gesture 2011(FG), 927-932. doi:10.1109/FG.2011.5771375

[12] Eguchi, A. (2016). Robo Cup Junior for promoting STEM education, 21st century skills, and technological advancement through robotics competition. Robotics and Autonomous Systems, 75, 692-699.https://doi.org/10.1016 /J.ROBOT.2015.05.013
[13] Ertmer, P. A., \& Ottenbreit-Leftwich, A. (2013). Removing obstacles to the pedagogical changes required by Jonassen's vision of authentic technology-enabled learning. Computers \& Education, 64, 175-182.https://doi.org/10.10 16/J.COMPEDU.2012.10.008

[14] Etikan, I., Musa, S. A., \& Alkassim, R. S. (2016), Comparison of convenience sampling and purposive sampling. American Journal of Theoretical and Applied Statistics, 5, 1-4.https://doi.org/10.11648/j.ajtas.20160501. 11

[15] Garcia-Murillo, M., MacInnes, I., \& Bauer, J. M. (2018). Techno-unemployment: A framework for assessing the effects of information and communication technologies on work. Telematics and Informatics, 35(7), 1863-1876. https://doi.org/10.1016/J.TELE.2018.05.013

[16] Gerecke, U., \& Wagner, B. (2007). The challenges and benefits of using robots in higher education. Intelligent Automation \& Soft Computing, 13(1), 29-43. https://doi.org/10.1080/10798587.2007.10642948

[17] Heerink, M., Kröse, B., Evers, V., \& Wielinga, B. (2010). Relating conversational expressiveness to social presence and acceptance of an assistive social robot. Virtual Reality, 14(1), 77-84. doi: https://doi.org/10.1007/s10055-009-014 $2-1$

[18] International Federation of Robotics. (2017). Executive Summary World Robotics 2017 Industrial Robots Report. Retrieved from https://ifr.org/downloads/press/Executive_ Summary_WR 2017 Industrial_Robots.pdf

[19] International Federation of Robotics. (2018). World Robotics Report 2018. Retrieved fromhttps://ifr.org/ifr-pre ss-releases/news/global-industrial-robot-sales-doubled-ove r-the-past-five-years

[20] Jones, V., Jo, J. H., \& Han, J. (2006). The Future of Robot-Assisted Learning in the Home. International Journal of Pedagogies and Learning, 2(1), 63-75. https://doi.org/10 .5172/ijpl.2.1.63

[21] Kandlhofer, M., \& Steinbauer, G. (2016). Evaluating the impact of educational robotics on pupils' technical- and social-skills and science related attitudes. Robotics and Autonomous Systems, 75, 679-685.https://doi.org/10.1016 /j.robot.2015.09.007

[22] Kerly, A., Hall, P., \& Bull, S. (2006). Bringing chatbots into education: Towards natural language negotiation of open learner models. Knowledge-Based Systems, 20(2), 177-185. https://doi.org/10.1016/J.KNOSYS.2006.11.014

[23] Khatib, O., Yokoi, K., Brock, O., Chang, K. S., \& Casal, A. (1999). Robots in human environments. Proceedings of the First Workshop on Robot Motion and Control, RoMoCo'99 (Cat. No.99EX353), 213-221. doi: 10.1109/ROMOCO.199 9.791078

[24] Kim, C., Kim, D., Yuan, J., Hill, R. B., Doshi, P., \& Thai, C. N. (2015). Robotics to promote elementary education pre-service teachers' STEM engagement, learning, and teaching. Computers \& Education, 91, 14-31. https://doi.org/10.1016/J.COMPEDU.2015.08.005

[25] Koc, M. (2013). Student teachers' conceptions of technology: A metaphor analysis. Computers and Education, 68, 1-8. https://doi.org/10.1016/j.compedu.2013.04.024 
[26] Kuo, I. H., Rabindran, J. M., Broadbent, E., Lee, Y. I., Kerse, N., Stafford, R. M. Q., MacDonald, B. A. (2009). Age and gender factors in user acceptance of healthcare robots. RO-MAN 2009 - The 18th IEEE International Symposium on Robot and Human Interactive Communication, 214-219. doi: 10.1109/ROMAN.2009.5326292

[27] Levin, M., \& Hansen, J. (2008). Clicking to learn or learning to click: A theoretical and empirical investigation. College Student Journal, 42(2), 665-674.

[28] Mahmood, M. H., \& Rodriguez, P. R. (2017). Localization and Mapping of Cheap Educational Robot with Low Bandwidth Noisy IR Sensors. In Proceedings of the 6th International Conference on Pattern Recognition Applications and Methods (ICPRAM 2017), 583-590. doi: $10.5220 / 0006204305830590$

[29] Matarić, M. J. (2007). The robotics primer. Cambridge, Massachusetts: MIT Press. Retrieved fromhttps://mitpress. mit.edu/

[30] Mcdermott, D. (2006). Kurzweil's argument for the success of AI. Artificial Intelligence, 170, 1227-1233.https://doi.or g/10.1016/j.artint.2006.10.006

[31] Ministries of Education, Industry and Information Technology, and Human Resources and Social Security of the People's Republic of China. (2016). Guidelines on the Development Plan of Talents in the Manufacturing Industry. Retrieved fromhttp:/www.miit.gov.cn/n1146290/n438879 1/c5500114/content.html

[32] Moreno, D. V., \& Quevedo, E. (2015). Project-based learning using robots with open-source hardware and software. II Jornadas Iberoamaricanas de Innovación Educativa en el ámbito de las TIC Las Palmas de Gran Canaria, 12-13 de noviembre de 2015, 141-144. Retrieved from http://makespacemadrid.org/que-es-el-makespace/.

[33] Mubin, O., Stevens, C. J., Shahid, S., Al Mahmud, A., \& Dong, J. (2013). A review of the applicability of robots in education. Technology for Education and Learning, 1, 1-7. doi:10.2316/Journal.209.2013.1.209-0015

[34] Ospennikova, E., Ershov, M., \& Iljin, I. (2015). ScienceDirect Educational Robotics as an Inovative Educational Technology. Procedia-Social and Behavioral Sciences, 214, 18-26. https://doi.org/10.1016/j.sbspro.2015 .11 .588

[35] Park, S. (2010, October 22). Robot teachers invade South Korean classrooms. CNN news. Retrieved from http://edition.cnn.com/2010/TECH/innovation/10/22/south .korea.robot.teachers/index.html

[36] QS Top Universities. (2018). QS World Universities Rankings. Retrieved from https://www.topuniversities.com /university-rankings/world-university-rankings/2018

[37] Sampsel, D., Bharwani, G., Mehling, D., \& Smith, S. (2011). Robots as Faculty: Student and Faculty Perceptions. Clinical Simulation in Nursing, 7(6), 209-218. https://doi.org/10.1016/J.ECNS.2010.02.009

[38] Scaradozzi, D., Sorbi, L., Pedale, A., Valzano, M., \& Vergine, C. (2015). Teaching robotics at the primary school: an innovative approach. Procedia-Social and Behavioral Sciences, 174, 3838-3846. https://doi.org/10.1016/j.sbspro. 2015.01.1122

[39] Syrdal, D. S., Dautenhahn, K., Woods, S. N., Walters, M.
L., \& Koay, K. L. (2007). Looking Good? Appearance Preferences and Robot Personality Inferences at Zero Acquaintance. In AAAI spring Symposium: Multidisciplinary collaboration for socially assistive robotics, 86-92. Retrieved from http://www.aaai.org/Paper s/Symposia/Spring/2007/SS-07-07/SS07-07-019.pdf

[40] White House (2011, June 24). President Obama Launches Advanced Manufacturing Partnership. Retrieved November 11, 2018 from https://obamawhitehouse.archives.gov/the-p ress-office/2011/06/24/president-obama-launches-advance d-manufacturing-partnership

[41] Williams, B. (2016). An introduction to robotics. EE/ME 4290/5290 Mechanics and Control of Robotics Manipulators, Dr. Bob Productions, unpublished. Retrieved from https://www.ohio.edu/mechanical-faculty/williams/ht $\mathrm{ml} / \mathrm{PDF} /$ IntroRob.pdf

[42] World Economic Forum. (2018, May). Digital transformation initiative: Maximizing the return on digital investment. Retrieved from http://reports.weforum.org/digi tal-transformation/files/2018/05/201805-DTI-Maximizingthe-Return-on-Digital-Investments.pdf

[43] World Economic Forum. (2018, January). The next economic growth engine scaling fourth industrial revolution technologies in production. Retrieved from http:/www3.w eforum.org/docs/WEF Technology and Innovation The Next_Economic_Growth_Engine.pdf

[44] World Economic Forum. (2018, January). Eight futures of work: Scenarios and their implications. Retrieved from http://www3.weforum.org/docs/WEF_FOW_Eight_Future s.pdf

[45] World Economic Forum. (2018, January). Maximizing the return on digital investments. Retrieved from http://www3.weforum.org/docs/DTI_Maximizing_Return_ Digital_WP.pdf

[46] World Economic Forum. (2016, January). The future of jobs: Employment, skills and workforces for the fourth industrial revolution. Retrieved from http://www3.weforum.org/docs /WEF_Future_of_Jobs.pdf

[47] World Economic Forum. (2018, January). Towards a Reskilling Revolution: A Future of Jobs for All. Retrieved from https://www.weforum.org/reports/towards-a-reskillin g-revolution

[48] World Economic Forum. (2018, March). Future of Consumption in Fast-Growth Consumer Markets: China. Retrieved from https://www.weforum.org/reports/future-of -consumption-in-fast-growth-consumer-markets-china

[49] World Economic Forum. (2017, March). Shaping the Future of Production: Four Contrasting Perspectives in 2030. Retrieved from https://www.weforum.org/whitepapers/sha ping-the-future-of-production-four-contrasting-perspective s-in-2030

[50] Yang, J., \& Qiao F. T. (2017). Report on the research of robotics education in primary and middle schools in China. Retrieved from http://www.xinhuanet.com/science/201709 05jqr/pdf/2017_08_30.pdf

[51] Zadok, Y., \& Voloch, N. (2018). Applying PBL to teaching robotics. International Journal of Innovation and Learning, 24(2), 138 -151. doi: 10.1504/IJIL.2018.094068 